\title{
Contribution of Invariant Natural Killer T Cells to Skin Wound Healing
}

Hiromasa Tanno, ${ }^{*}$ Kazuyoshi Kawakami, ${ }^{\dagger}$ Masae Ritsu, ${ }^{*}$ Emi Kanno, ${ }^{\ddagger}$ Aiko Suzuki, ${ }^{*}$ Rina Kamimatsuno, ${ }^{*}$ Naoyuki Takagi, * Tomomitsu Miyasaka, ${ }^{\dagger}$ Keiko Ishii, ${ }^{\dagger}$ Yoshimichi Imai, ${ }^{*}$ Ryoko Maruyama, ${ }^{\ddagger}$ and Masahiro Tachi*

From the Departments of Plastic and Reconstructive Surgery, ${ }^{*}$ Medical Microbiology, Mycology and Immunology, ${ }^{\dagger}$ and Science of Nursing Practice, ${ }^{\ddagger}$ Tohoku University Graduate School of Medicine, Aoba-ku, Sendai, Japan

Accepted for publication August 28, 2015.

Address correspondence to Masahiro Tachi, M.D., Ph.D. Department of Plastic and Reconstructive Surgery, Tohoku University Graduate School of Medicine, 2-1 Seiryocho, Aoba-ku, Sendai, Miyagi 980-8575, Japan. E-mail: tachi@med.tohoku.ac.jp.

\begin{abstract}
In the present study, we determined the contribution of invariant natural killer T (iNKT) cells to the skin wound healing process. In iNKT cell-deficient (J $\alpha 18 K 0)$ mice lacking iNKT cells, wound closure was significantly delayed compared with wild-type mice. Collagen deposition, expression of $\alpha$-smooth muscle actin and CD31, and wound breaking strength were significantly attenuated in J $\alpha 18 \mathrm{~K} 0$ mice. The adoptive transfer of liver mononuclear cells from wild-type but not from J $\alpha 18$ K0 or interferon (IFN)- $\gamma$ gene-disrupted (IFN- $\gamma \mathrm{KO}$ ) mice resulted in the reversal of this impaired wound healing in J $\alpha 18 \mathrm{KO}$ mice. IFN- $\gamma$ expression was induced in the wounded tissues, which was significantly decreased at 6,12 , and 24 hours, but increased on day 3 after wounding in J $\alpha 18$ KO mice. The main source of the late-phase IFN $-\gamma$ production in J $\alpha 18$ KO mice were neutrophils rather than NK cells and T cells. Administration of $\alpha$-galactosylceramide, an activator of $i N K T$ cells, resulted in the acceleration of wound healing on day 3 in wild-type mice. This effect was not observed in IFN- $\gamma \mathrm{KO}$ mice. These results indicate that iNKT cells play important roles in wound healing. The $i$ NKT cell-induced IFN- $\gamma$ production may regulate the wound healing process in the early phase. (Am J Pathol 2015, 185: 3248-3257; http://dx.doi.org/10.1016/ j.ajpath.2015.08.012)
\end{abstract}

The wound healing process consists of coagulation, inflammation, proliferation, and remodeling phases, which involve a variety of cytokines and growth factors. ${ }^{1-4}$ Both immune and nonimmune cells, including macrophages, neutrophils, fibroblasts, vascular endothelial cells, and keratinocytes, are involved in wound healing.

$\mathrm{T}$ cells and other immune cells may become involved at later stages such as scar formation. ${ }^{5}$ However, research has found that the epidermal $\gamma \delta \mathrm{T}$ cells promote wound healing by attracting macrophages to the wound bed and modulating the extracellular matrix. ${ }^{6}$ In addition, a direct comparison of $\mathrm{T}$ cells from acute and chronic wounds found that both $\alpha \beta$ and $\gamma \delta$ epidermal $\mathrm{T}$ cells were activated and produced growth factors only in acute wounds.

Invariant natural killer $\mathrm{T}(i \mathrm{NKT})$ cells are a unique lymphocyte subset distinct from $\mathrm{T}, \mathrm{B}$, and NK cells and are identified by the co-expression of both $\alpha \beta$ T-cell antigen receptor and NK-cell marker. These cells are typically characterized by the expression of a single invariant $\alpha$ chain in the antigen receptor encoded by a rearranged $\mathrm{V} \alpha 14-\mathrm{J} \alpha 18$ gene segment coupled with a highly skewed $\beta$ chain, such as $\mathrm{V} \beta 8.2$, V $\beta 7$, or V $\beta 2 .^{8-10} \alpha$-Galactosylceramide ( $\alpha$-GalCer), a synthetic glycolipid originally isolated from marine sponges, is recognized in a specific manner by $i$ NKT cells in contact with CD1d expressed on antigen-presenting cells, which results in the production of both interferon (IFN)- $\gamma$ and IL-4. ${ }^{8-10} i$ NKT cells play an important role in various aspects of the regulation and effector arms of immune responses, including the regulation of allergic and autoimmune diseases, prevention of tumor metastasis, and protection against bacterial, fungal, and parasitic infections. ${ }^{8-13}$ Schneider et $\mathrm{al}^{14,15}$ reported that when NKT cells were absent, initial wound healing was markedly accelerated. However, it is not fully understood how this particular

\footnotetext{
Supported in part by the Ministry of Education, Culture, Sports, Science, and Technology of Japan grants-in-aid for scientific research (B) 21390476 and (C) 24592705 (M.T.).

Disclosures: None declared.

Current address of T.M., Department of Pathophysiology, Tohoku Pharmaceutical University, Aoba-ku, Sendai, Miyagi, Japan.
} 
lymphocyte subset is involved in the process of wound healing.

Here, to determine whether $i$ NKT cells mediate acute wound healing, we monitored the wound healing process after full-thickness wounding in mice lacking $i$ NKT cells. We found that $i$ NKT cells contribute to the skin wound healing process by inducing the early-phase production of IFN- $\gamma$.

\section{Materials and Methods}

\section{Animals}

$i$ NKT cell-deficient $(\mathrm{J} \alpha 18 \mathrm{KO})$ mice, established by targeted deletion of the $\mathrm{J} \alpha 18$ gene segment, ${ }^{16}$ were kindly provided by Dr. Toshinori Nakayama (Chiba University, Chiba, Japan). IFN- $\gamma$ gene-disrupted (IFN- $\gamma \mathrm{KO}$ ) mice were provided by Dr. Yoichiro Iwakura (Tokyo University of Science, Tokyo, Japan). ${ }^{17}$ These mice were backcrossed more than eight times with C57BL/6 mice. Wild-type (WT) C57BL/6 mice, purchased from CLEA Japan (Tokyo, Japan), were used as a control. Male or female mice at 6 to 10 weeks old were used in the experiments. All mice were bred in a pathogen-free environment in the Institute for Animal Experimentation, Tohoku University Graduate School of Medicine (Sendai, Japan). All experimental protocols described in the present study were approved by the Ethics Review Committee for Animal Experimentation of Tohoku University.

\section{Wound Creation and Tissue Collection}

Mice (6 to 10 weeks of age) were anesthetized with an intraperitoneal injection of $40 \mathrm{mg} / \mathrm{kg}$ sodium pentobarbital (Nembutal Injection; Dainippon Sumitomo Pharma, Osaka, Japan). The dorsal hairs were shaved to fully expose the skin, which was then rinsed with $70 \%$ ethanol. Six full-thickness wounds extending to the panniculus carnosus were created with a 3-mm-diameter biopsy punch (Kai Industries Co., Ltd., Gifu, Japan) under sterile conditions. The six wounds per mouse were at least $5 \mathrm{~mm}$ from each other. The injured areas were covered with a polyurethane film (Tegaderm Transparent Dressing; 3M Health Care, St. Paul, MN) and an elastic adhesive bandage (Hilate, Iwatsuki, Tokyo, Japan) for an occlusive dressing. At various time points, mice were sacrificed, and the wound tissues were collected by excising the area with the use of an 8 -mm-diameter biopsy punch. The tissues were processed for histologic analysis and measurement of cytokine concentrations.

\section{Reagents and Antibodies}

$\alpha$-GalCer was purchased from Funakoshi (Tokyo, Japan) and dissolved in dimethyl sulfoxide at $5 \mathrm{mg} / \mathrm{mL}$, which was diluted with phosphate-buffered saline (PBS). The final dose for use in vivo was $0.2 \%$ dimethyl sulfoxide in PBS. Therefore, PBS that contained $0.2 \%$ dimethyl sulfoxide was used as the control vehicle. To activate $i$ NKT cells, mice were injected intraperitoneally with $\alpha$-GalCer (2 $\mu \mathrm{g}$ per mouse) on day 1 before and on day 3 after wound creation.

\section{Measurement of Wound Area}

Morphometric analysis was performed on digital images with the use of a digital camera (CX4; Ricoh, Tokyo, Japan). After the wounds were created, photographs were taken of each wound before dressing. At various time points, the polyurethane films were gently removed from the sacrificed mice, and the wounds were photographed. The wound area was quantified by tracing its margin and calculating the pixel area with the use of AxioVision imaging software Release 4.6 (Carl Zeiss Micro Imaging Japan, Tokyo, Japan). Wound healing was evaluated as percentage of wound closure, which was calculated with the use of the following formula: percentage of wound closure $=(1-$ wound area at the indicated time point/ wound area on day 0$) \times 100$.

\section{Preparation of Leukocytes in the Wound Tissues}

Mice were sacrificed before or at 6, 12, and 24 hours after wounding. The wound tissues excised with an 8-mmdiameter biopsy punch were incubated in RPMI 1640 medium (Nipro, Osaka, Japan) that was supplemented with $10 \%$ fetal calf serum (FCS; BioWest, Nuaillé, France) and 1 $\mathrm{mg} / \mathrm{mL}$ dispase (Roche Diagnostics, Tokyo, Japan) at $4^{\circ} \mathrm{C}$ for 16 hours and then incubated with vigorous shaking in 10\% FCS RPMI 1640 medium that was supplemented with $10 \mathrm{mmol} / \mathrm{L}$ HEPES (Sigma-Aldrich, St. Louis, MO) that contained $1 \mathrm{mg} / \mathrm{mL}$ collagenase, $1 \mathrm{mg} / \mathrm{mL}$ hyaluronidase (Sigma-Aldrich), and $1 \mathrm{mg} / \mathrm{mL}$ DNase I (Roche Diagnostics) at $37^{\circ} \mathrm{C}$ for 2 hours. After these treatments, the tissues were passed through a $70-\mu \mathrm{m}$ nylon mesh (BD Falcon, Bedford, MA), then washed three times with $1 \%$ FCS RPMI 1640 medium and used as skin leukocyte for flow cytometric analysis.

\section{Flow Cytometry}

The skin leukocytes were preincubated with anti-Fc $\gamma$ RIII monoclonal antibody (mAb), prepared from the culture supernatant fluids of hybridoma cells (clone 2.4G2) with the use of a protein $\mathrm{G}$ column kit (Kirkegaard \& Perry Laboratories, Gaithersburg, MD), on ice for 15 minutes in PBS that contained $1 \%$ FCS and $0.1 \%$ sodium azide. The cells were stained with phosphatidylethanolamine-conjugated anti-NK1.1 mAb (clone PK136; e-Bioscience, San Diego, $\mathrm{CA}$ ), allophycocyanin-conjugated anti-CD3e mAb (clone 145-2C11; BioLegend, San Diego, CA), and eFluor 


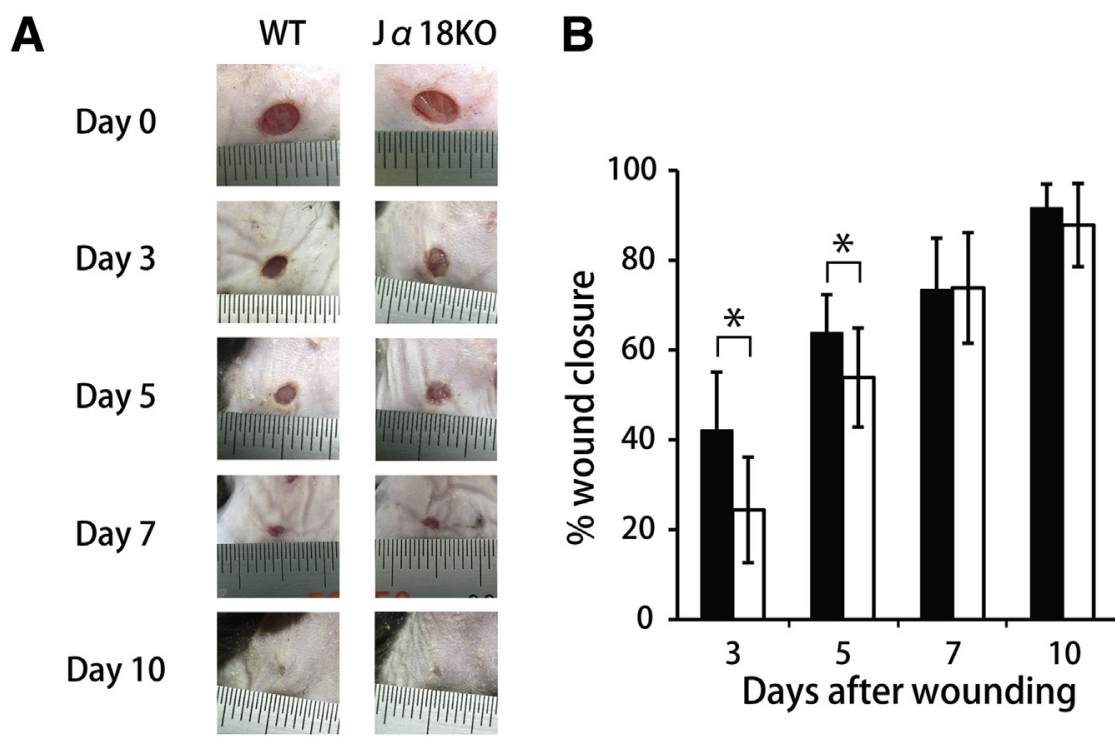

C

Day 5

WT
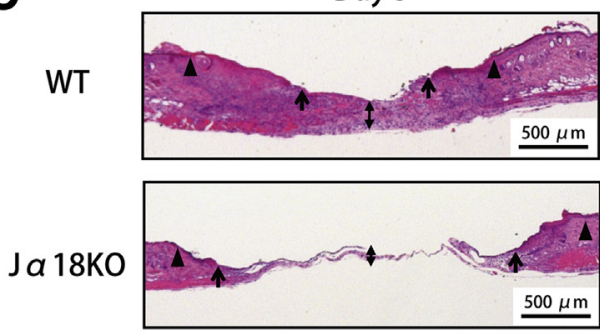

Figure 1 Effect of $\mathrm{J} \alpha 18$ depletion on skin wound healing. A and $\mathbf{B}$ : Wounds were created on the backs of $\mathrm{J} \alpha 18 \mathrm{~K} 0$ (white bars) or WT (black bars) mice, the photographs (A) were taken, and percentages of wound closure (B) were evaluated on days $3,5,7$, and 10. C: Representative histologic views of skin wounds on day 5 and 7. Arrowheads, arrows, and doubleheaded arrows indicate the original wound edges, reepithelialized leading edges, and HD, respectively. D: Time-course changes in the HD after wound creation. E: Time-course changes in the re-epithelialization ratio after wound creation. Percentage of reepithelialization was calculated by measuring the distance between the leading edges and the width of the wound bed, as described in Materials and Methods. Each column represents the means \pm SD. $n=18$ to $24(\mathbf{A}$ and $\mathbf{B}) ; n=9(\mathbf{D}$ and $\mathbf{E}) .{ }^{*} P<0.05$. HD, height of the dermis; J $\alpha 18 \mathrm{~K} 0$, invariant natural killer $\mathrm{T}$ celldeficient; WT, wild-type.
D

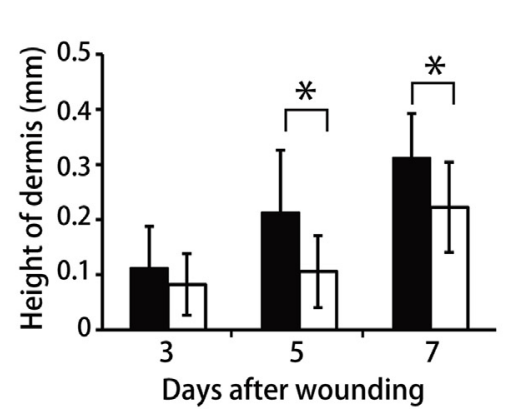

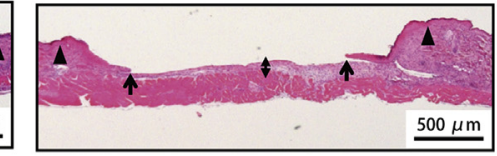

E

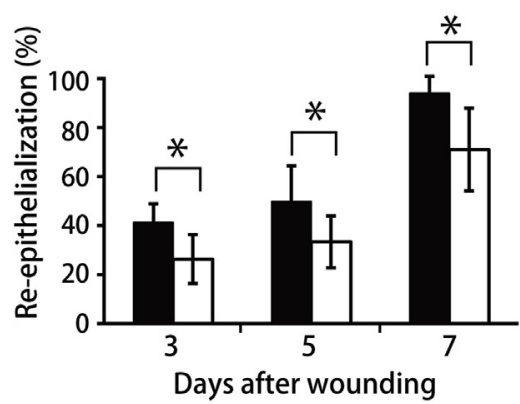

Days after wounding

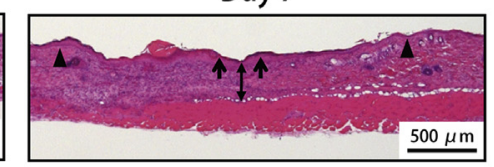

450-conjugated anti-CD45 mAb (clone 30-F11; e-Bioscience). In some experiments, the cells were stained with phosphatidylethanolamine-conjugated anti-CD11b (clone M1/70; BioLegend) and fluorescein isothiocyanateconjugated anti-Gr-1 mAb (clone RB6-8C5; BioLegend). Isotype-matched antibodies were used for control staining. To stain intracellularly expressed IFN- $\gamma$, skin leukocytes were incubated in the presence of Cytofix/Cytoperm (BD Biosciences, Franklin Lakes, NJ), washed twice in BD perm/wash solution, and stained with phosphatidylethanolamine-cyanine-7-conjugated anti-IFN- $\gamma \mathrm{mAb}$ (clone XMG1.2; BioLegend) or control rat IgG. The stained cells were analyzed with a BD FACS Canto II flow cytometer (BD Bioscience). The leukocytes were analyzed as CD $45^{+}$cells, and NK cells, NKT cells, conventional $\mathrm{T}$ cells, and neutrophils were defined as $\mathrm{NK} 1.1^{+} \mathrm{CD} 3^{-}$ cells, NK1.1 $1^{+} \mathrm{CD}^{+}$cells, $\mathrm{NK} 1.1^{-} \mathrm{CD}^{+}$cells, and $\mathrm{Gr}-1^{\text {bright }+} \mathrm{CD} 11 \mathrm{~b}^{\text {bright }+}$ cells, respectively.

\section{Preparation of LMNCs}

Liver mononuclear cells (LMNCs) were prepared as described previously with some modification. ${ }^{18}$ Briefly, livers were excised from mice anesthetized with ether and teased apart with the use of a stainless-steel mesh in RPMI 1640 medium supplemented with $5 \mathrm{mmol} / \mathrm{L}$ HEPES and $2 \%$ FCS. After washing, the pellets were suspended in $15 \mathrm{~mL}$ of 35\% Percoll solution (Pharmacia, Uppsala, Sweden) containing $100 \mathrm{U} / \mathrm{mL}$ heparin and centrifuged at $760 \times g$ for 15 minutes at $20^{\circ} \mathrm{C}$. The pellet was then resuspended in red blood cell lysis solution $\left(155 \mathrm{mmol} / \mathrm{L} \mathrm{NH}_{4} \mathrm{Cl}\right.$ and $17 \mathrm{mmol} / \mathrm{L}$ Tris, $\mathrm{pH}$ 7.2) and washed twice with RPMI 1640 that 


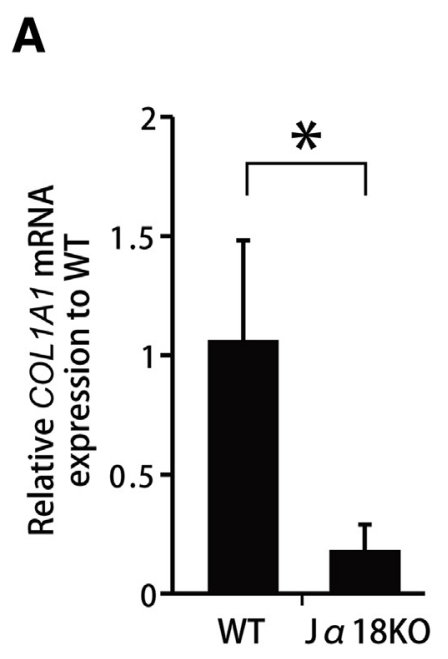

D

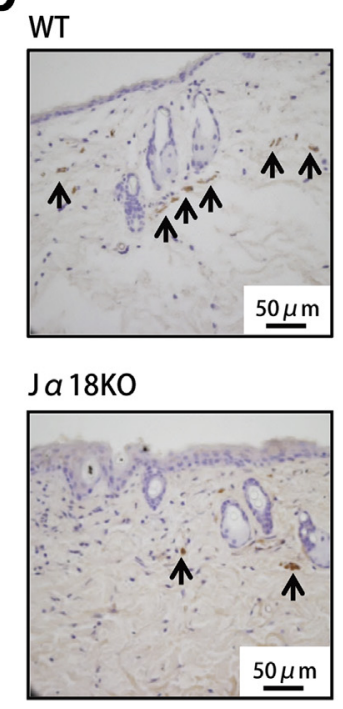

B

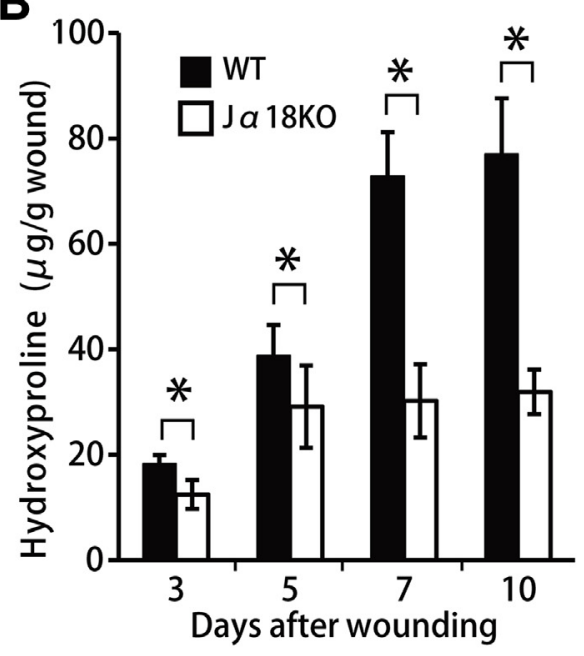

E
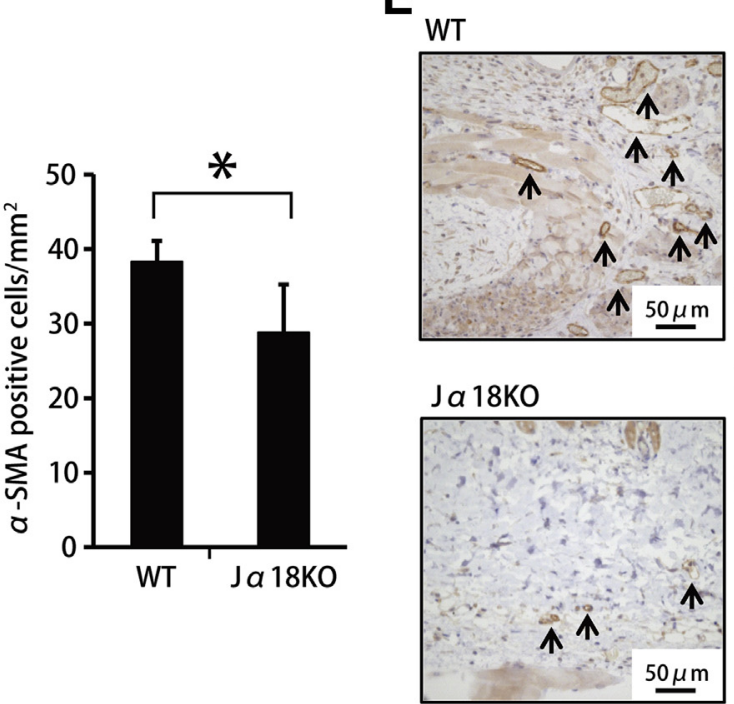

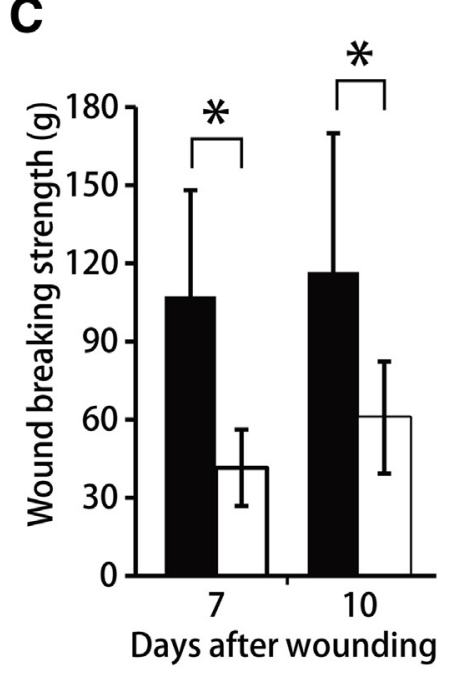

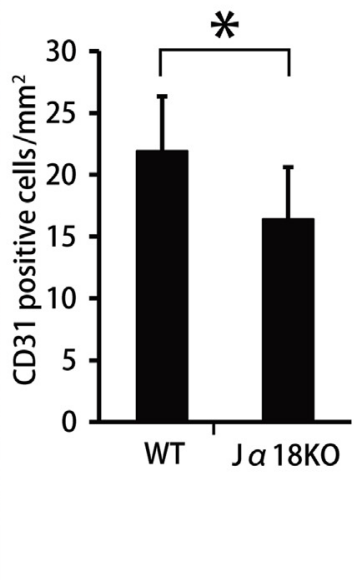

Figure 2 Effect of J $\alpha 18$ depletion on collagen deposition, myofibroblast differentiation, and angiogenesis. A: Real-time PCR was performed for the detection of COL1A1 mRNA with the use of total RNA isolated from wound tissues on day 3. HPRT was used as an internal control. B: Hydroxyproline content was evaluated on days 3, 5, 7, and 10. C: Wound breaking strength was measured on days 7 and 10 after wounding. D: Images show myofibroblasts stained with anti- $\alpha$-SMA antibody on day 3. Arrows indicate $\alpha-S M A^{+}$cells. The $\alpha-S M A^{+}$cells $/ \mathrm{mm}^{2}$ on day 3 determined by counting the number of $\alpha-\mathrm{SMA}^{+}$cells within five visual fields under microscopic observation are shown. E: Images show CD31 ${ }^{+}$cells stained with anti-CD31 antibody on day 3. Arrows indicate $\mathrm{CD} 31^{+}$cells. The vascular density per $\mathrm{mm}^{2}$ was determined by counting the positive vessels within five visual fields. $n=6$ $(\mathbf{A}$ and $\mathbf{B}) ; n=18(\mathbf{C}) ; n=9$ (D and $\mathbf{E})$. ${ }^{*} P<0.05$. Original magnification, $\times 400$. HPRT, hypoxanthine phosphoribosyltransferase; J $\alpha 18 \mathrm{~K} 0$, invariant natural killer T cell-deficient; WT, wild-type; $\alpha$-SMA, $\alpha$-smooth muscle actin.

contained $1 \%$ FCS. LMNCs were injected intravenously at $1 \times 10^{6}$ per mouse 1 day before wound creation.

\section{Extraction of RNA and Quantitative Real-Time RT-PCR}

Total RNA was extracted from wound tissues with the use of ISOGEN (Nippon Gene Co. Ltd., Tokyo, Japan) according to the manufacturer's instructions. The first-strand cDNA was synthesized with a PrimeScript first-strand cDNA synthesis kit (TaKaRa Bio Inc., Shiga, Japan), according to the manufacturer's instructions. Quantitative real-time RT-PCR was performed in a volume of $20 \mu \mathrm{L}$ with the use of gene-specific primers and FastStart essential DNA green master mix (Roche
Applied Science, Branford, CT) in a LightCycler nanosystem (Roche Applied Science). Primers for IFN- $\gamma$, IL-4, and hypoxanthine phosphoribosyltransferase were shown in our previous study, ${ }^{19}$ and primers for COL1A1 were as follows: $5^{\prime}$-AAGACAAGGCAGCGGTGGAA-3' (forward) and 5'-GCAGGGGACAGGAAATAGTT-3' (reverse). Reaction efficiency with each primer set was determined with standard amplifications. Target gene expression levels and that of hypoxanthine phosphoribosyltransferase as a reference were calculated for each sample with the use of the reaction efficiency. The results were analyzed with a relative quantification procedure and are presented as expression relative to hypoxanthine phosphoribosyltransferase expression. 


\section{Analysis of Hydroxyproline Content}

Mice were sacrificed on day 3 after wounding, wounds were removed with an 8-mm-diameter biopsy punch, and total wound hydroxyproline content was assayed. Briefly, all wounds were homogenized and then hydrolyzed in $6 \mathrm{~N} \mathrm{HCl}$ for 21 hours at $120^{\circ} \mathrm{C}$. The hydrolysate was neutralized with $\mathrm{NaOH}$. In the next step, 2-mL aliquots were analyzed calorimetrically for hydroxyproline content after addition of $1 \mathrm{~mL}$ of $0.05 \mathrm{~mol} / \mathrm{L}$ chloramine $\mathrm{T}$ (Nacalai Tesque, Kyoto, Japan), $1 \mathrm{~mL}$ of $3.15 \mathrm{~mol} / \mathrm{L}$ perchloic acid (Nacalai Tesque), and $1 \mathrm{~mL}$ of $20 \%$ dimethylaminobenzaldehyde (Nacalai Tesque). The optical density of the samples was determined with a spectrophotometer at $557 \mathrm{~nm}$.

\section{Histologic Analysis}

The wound tissues that were collected with an 8-mm-diameter biopsy punch were dissected in a caudocranial direction. The tissues were fixed with $4 \%$ paraformaldehyde-phosphate buffer solution and embedded in paraffin. Sections of 2- $\mu$ m thickness were harvested from the central portion of the wound and stained with hematoxylin and eosin, according to the standard method. The extent of re-epithelialization of each wound was measured in these hematoxylin and eosin-stained sections by measuring the distance from the normal wound margin to the edge of the epithelium. The re-epithelialization index was determined on the basis of the percentage of new epithelium present in the total wound. The height of the dermis in the center of the wounds was determined on hematoxylin and eosinstained sections. For immunohistochemistry, the sections were stained with anti-CD31 antibody (dilution 1:600; Santa Cruz Biotechnology, Santa Cruz, CA) and anti- $\alpha$-smooth muscle actin ( $\alpha$-SMA) antibody (dilution 1:200; Vector Laboratories, Inc., Burlingame, CA) after endogenous peroxidase and nonspecific binding were blocked. They were then incubated with peroxidase-conjugated secondary antibodies (Histofine Simple Stain MAX-PO; Nichirei Bioscience, Tokyo, Japan). Control sections were treated with nonimmune IgG in place of any of the first antibodies. Five fields $\left(0.2 \mathrm{~mm}^{2}\right.$ in area each $)$ were selected and analyzed under $\times 400$ magnification (Olympus BH-2; Olympus Optical Co., Ltd., Tokyo, Japan).

\section{Wound Breaking Strength}

The wounded skin, harvested from WT and $i$ NKT celldeficient $(\mathrm{J} \alpha 18 \mathrm{KO})$ mice on days 7 and 10 after wounding, was excised in a strip $5 \mathrm{~mm}$ away from the center of the wound with the use of a no. 15 surgical blade (Feather Safety Razor Co., Ltd., Osaka, Japan). Wound breaking strength was measured with IMS-001 (Keisei Medical Industrial Co., Ltd., Tokyo, Japan), as previously described. ${ }^{20}$ Briefly, each side of the strip was pinched by a clip and then pulled at a constant speed of $3 \mathrm{~cm} /$ minute until it broke away. The result was expressed as the tensile force necessary to break the repaired wounds.
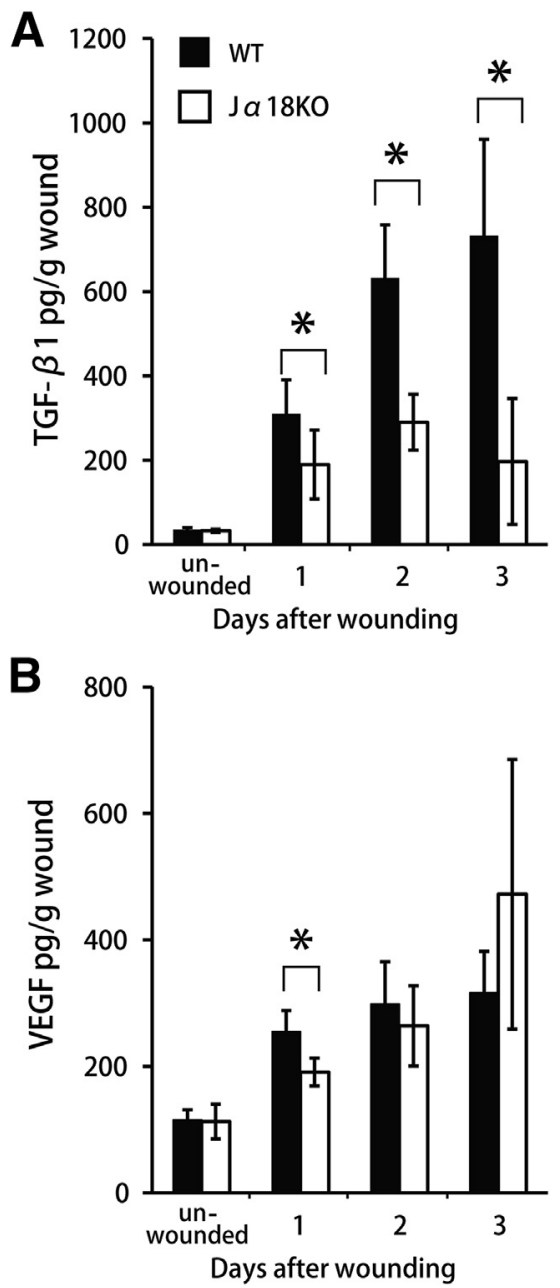

Figure 3 Effect of $\mathrm{J} \alpha 18$ depletion on the production of TGF- $\beta 1$ and VEGF. A: Production of TGF- $\beta 1$ in the homogenates of wound tissues was measured in unwounded tissues on days 1,2 , and 3 after wound creation. B: Production of VEGF in the homogenates of wound tissues was measured in unwounded tissues on days 1,2 , and 3 after wound creation. $n=5$. ${ }^{*} P<0.05$. J $\alpha 18 \mathrm{~K} 0$, invariant natural killer $\mathrm{T}$ cell-deficient; TGF, transforming growth factor; VEGF, vascular endothelial growth factor; WT, wild-type.

\section{Measurement of TGF- $\beta 1$ and VEGF Concentrations}

The wound tissues were homogenated with PBS, and concentrations of transforming growth factor (TGF)- $\beta 1$ and vascular endothelial growth factor (VEGF) in the supernatant fluids were measured by enzyme-linked immunosorbent assay kits (eBioscience for TGF- $\beta 1$ and R\&D Minneapolis, MN, for VEGF). The results were expressed as the values per wound. The detection limit was $8 \mathrm{pg} / \mathrm{mL}$ for TGF- $\beta 1$ and VEGF.

\section{Statistical Analysis}

Data are expressed as means \pm SD. Data analysis was performed with the Welch's $t$-test. Statistical analysis between more than two groups was performed with an analysis 
A

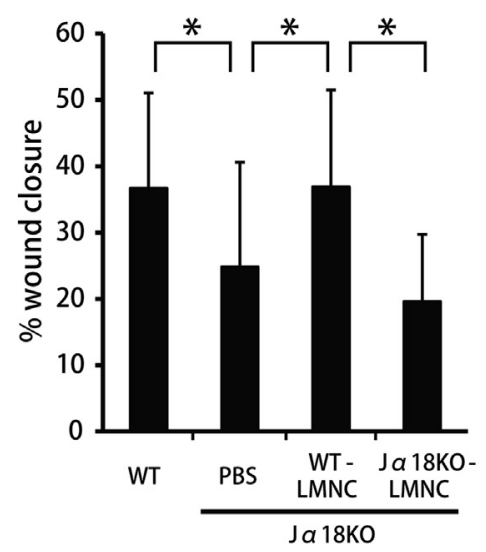

B

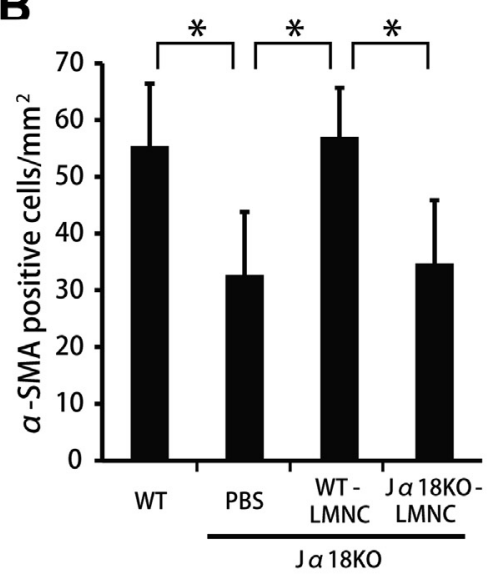

C

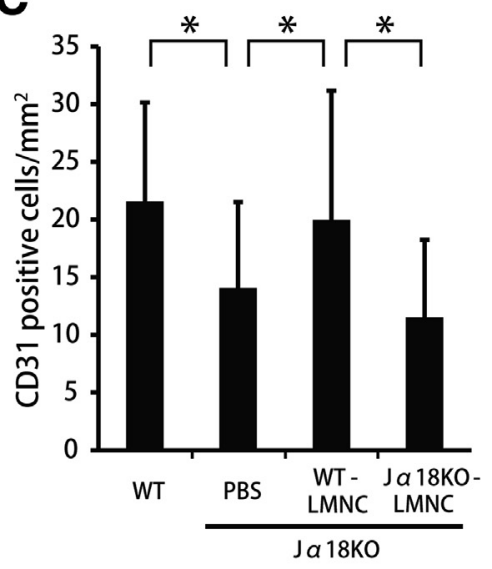

Figure 4 Effect of LMNC transfer on wound healing. Wounds were created on the backs of WT or J 1818 KO mice, which were injected with PBS or transferred with LMNCs $\left(1 \times 10^{6}\right.$ per mouse) obtained from WT or J $\alpha 18$ KO mice. Percentage of wound closure $(\mathbf{A}), \alpha-S M A^{+}$cells $/ \mathrm{mm}^{2}(\mathbf{B})$, and CD31 $1^{+}$cells $/ \mathrm{mm}^{2}(\mathbf{C})$ were evaluated on day 3. $n=18(\mathbf{A}) ; n=9$ (B and C). ${ }^{*} P<0.05$. J $\alpha 18 \mathrm{KO}$, invariant natural killer T cell-deficient; LMNC, liver mononuclear cell; PBS, phosphatebuffered saline; WT, wild-type; $\alpha$-SMA, $\alpha$-smooth muscle actin.

of variance (Dunnett's method). $P<0.05$ was considered significant.

\section{Results}

\section{Delayed Wound Healing in iNKT Cell-Deficient Mice}

To examine the possible contribution of $i$ NKT cells to the process of wound healing, the rate of wound closure of $\mathrm{J} \alpha 18 \mathrm{KO}$ mice was compared with that of WT mice. Wound closure was significantly delayed in $\mathrm{J} \alpha 18 \mathrm{KO}$ mice compared with that in WT mice on days 3 and 5, although no significant difference was detected on days 7 and 10 (Figure 1, A and B). In addition, J $\alpha 18 \mathrm{KO}$ mice showed significantly reduced height of the dermis and impaired reepithelialization compared with WT mice on days 5 and 7 after wounding (Figure 1, C-E). These results suggest that $i$ NKT cells may contribute substantially to the process of wound healing in skin.

\section{Collagen Deposition at the Wound Site}

We next analyzed the effect of $i$ NKT cells on collagen deposition. The gene expression of COL1Al was lower in $\mathrm{J} \alpha 18 \mathrm{KO}$ mice than in WT mice (Figure 2A). In addition, the content of collagen-specific amino acid hydroxyproline was significantly reduced in $\mathrm{J} \alpha 18 \mathrm{KO}$ mice compared with that in WT mice (Figure 2B). To further confirm the role of $i \mathrm{NKT}$ cells in the late-phase events, we measured the wound breaking strength on days 7 and 10 after wound creation. Consistent with the attenuation of collagen deposition, the wound breaking strength was significantly reduced in $\mathrm{J} \alpha 18 \mathrm{KO}$ mice compared with that in WT mice (Figure 2, B and $\mathrm{C}$ ). As alternate indicators of wound healing, we analyzed myofibroblast differentiation and angiogenesis. The number of both indicators was significantly decreased in $\mathrm{J} \alpha 18 \mathrm{KO}$ mice (Figure 2, D and E).

\section{TGF- $\beta 1$ and VEGF Production Attenuates in iNKT Cell-Deficient Mice}

We next addressed the involvement of $i$ NKT cells on synthesis of TGF- $\beta 1$ and VEGF, important cytokines for granulation tissue and angiogenesis development, respectively. TGF- $\beta 1$ production was significantly reduced in $\mathrm{J} \alpha 18 \mathrm{KO}$ mice compared with WT mice on days 1, 2, and 3 (Figure 3A). Furthermore, VEGF production was significantly reduced in J $\alpha 18 \mathrm{KO}$ mice compared with WT mice on day 1 , but not on days 2 and 3 (Figure 3B).

\section{Effect of LMNC Transfer on Wound Healing}

In addition, LMNCs from WT mice were transferred into $\mathrm{J} \alpha 18 \mathrm{KO}$ mice, and their effect on the rate of wound closure was tested. The impaired wound closure in $\mathrm{J} \alpha 18 \mathrm{KO}$ mice was almost completely reversed by the transfer of LMNCs obtained from WT mice, whereas this effect was not observed with cells derived from $\mathrm{J} \alpha 18 \mathrm{KO}$ mice (Figure 4A).

The decreased number of $\alpha$-SMA ${ }^{+}$cells and CD $31^{+}$cells in $\mathrm{J} \alpha 18 \mathrm{KO}$ mice was almost completely reversed by the transfer of LMNCs obtained from WT mice, whereas this effect was not observed with cells derived from J $\alpha 18 \mathrm{KO}$ mice (Figure 4, B and C). These results indicated that $i$ NKT cells contributed to wound healing.

\section{IFN- $\gamma$ and IL-4 mRNA Expression during Wound Healing}

Because $i$ NKT cells are well known to quickly secrete a robust amount of IFN- $\gamma$ and IL-4 after their activation, ${ }^{8-10}$ we examined IFN- $\gamma$ and IL-4 production in the wounded tissue. The expression of IFN- $\gamma$ mRNA in the wounded tissues reached peak levels at 12 hours in WT mice, whereas 
A

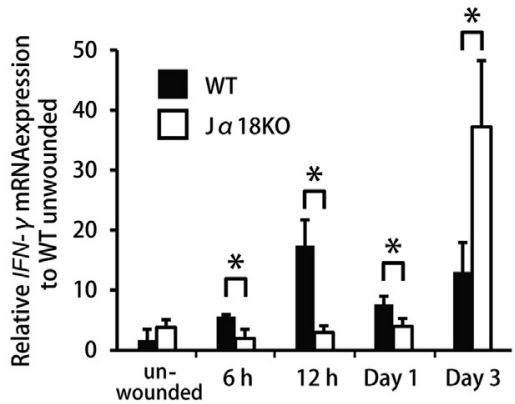

B
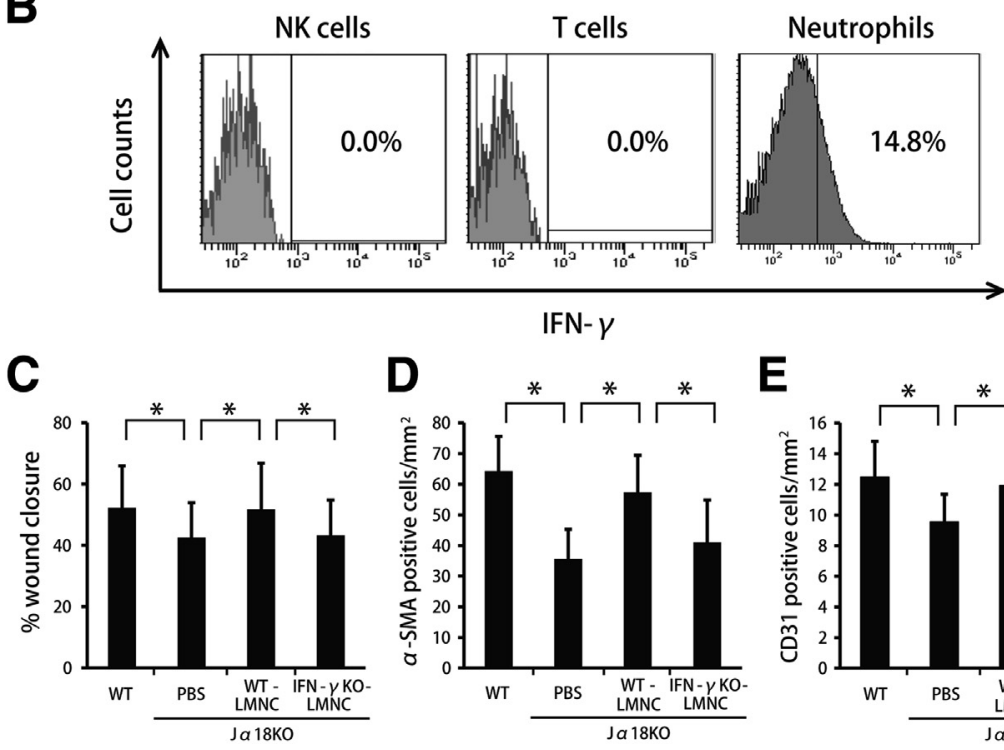

E

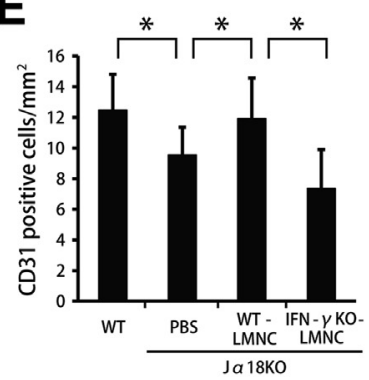

Figure 5 Effect of Ja18 deficiency on IFN- $\gamma$ synthesis and $i$ NKT cell-derived IFN- $\gamma$ contributes to skin wound healing. A: Expression of IFN- $\gamma$ mRNA in wound tissues from WT or J $118 \mathrm{~K} 0$ mice was measured by real-time PCR. Next, J $\alpha 18 \mathrm{~K} 0$ mice received LMNCS $\left(1 \times 10^{6}\right.$ per mouse) intravenously derived from WT or IFN- $\gamma$ KO mice 24 hours before wound creation. B: IFN- $\gamma$ expression in NK cells, T cells, and neutrophils at the wound sites on day 3 in J $\alpha 18 \mathrm{~K} 0$ mice. Cutoff line is determined in each subset on the basis of the staining profile with isotype control for anti-IFN- $\gamma$ monoclonal antibody. Percentage of wound closure (C), $\alpha$-SMA ${ }^{+}$ cells $/ \mathrm{mm}^{2}(\mathbf{D})$, and ${\mathrm{CD} 31^{+}}^{+}$cells $/ \mathrm{mm}^{2}(\mathrm{E})$ were evaluated on day $3 . n=6($ A) $; n=18($ C) $; n=9$ (D); $n=9$ (E). ${ }^{*} P<0.05$. IFN, interferon; IFN$\gamma K 0, I F N-\gamma$ gene-disrupted; iNKT, invariant natural killer T; J $\alpha 18 K 0$, iNKT cell-deficient; LMNC, liver mononuclear cell; NK, natural killer; PBS, phosphate-buffered saline; WT, wild-type; $\alpha$-SMA, $\alpha$-smooth muscle actin.
IFN- $\gamma$ expression in $\mathrm{J} \alpha 18 \mathrm{KO}$ mice remained unchanged. In contrast, J $\alpha 18 \mathrm{KO}$ mice exhibited a dramatic increase in the expression of IFN- $\gamma$ mRNA on day 3 (Figure 5 A). In further experiments, we examined the cells contributing to the increased expression of IFN- $\gamma$ on day 3 in $\mathrm{J} \alpha 18 \mathrm{KO}$ mice. NK cells and T cells did not express IFN- $\gamma$, but neutrophils showed a considerable expression of this cytokine (Figure 5B). However, IL-4 mRNA expression was not detected at the wound site in two groups (data not shown).

\section{iNKT Cell-Derived IFN- $\gamma$ Contributes to Skin Wound Healing}

To explore if $i$ NKT cell-derived IFN- $\gamma$ contributed to wound healing, LMNCs from WT or IFN- $\gamma$ KO mice were transferred into J $\alpha 18 \mathrm{KO}$ mice. The impaired wound closure in $\mathrm{J} \alpha 18 \mathrm{KO}$ mice was almost completely reversed by the transfer of LMNCs obtained from WT mice, whereas this effect was not observed with cells derived from IFN- $\gamma \mathrm{KO}$ mice (Figure $5 \mathrm{C}$ ). The decreased number of $\alpha$-SMA ${ }^{+}$cells and $\mathrm{CD} 31^{+}$cells in $\mathrm{J} \alpha 18 \mathrm{KO}$ mice was almost completely reversed by the transfer of LMNCs obtained from WT mice, whereas this effect was not observed with cells derived from IFN- $\gamma \mathrm{KO}$ mice (Figure 5, D and E). These results suggest that $i$ NKT cell-derived IFN- $\gamma$ contributed to wound healing.

\section{Effect of $\alpha$-GalCer Administration on Wound Healing}

To further confirm the possible contribution of $i$ NKT cells, we examined the effect of administration of $\alpha$-GalCer, which activates $i$ NKT cells in a specific manner, on the process of wound healing. Administration of $\alpha$-GalCer significantly promoted wound closure compared with treatment with the vehicle on day 3 , but not on day 5 , in the early phase of wound healing (Figure 6A). Likewise, collagen deposition and the number of $\mathrm{CD} 31^{+}$cells were increased in the $\alpha$-GalCer-treated group compared with the control group (Figure 6, B and E). However, the production of TGF- $\beta 1$, number of $\alpha-\mathrm{SMA}^{+}$cells, and synthesis of VEGF was not significantly different between the two groups (Figure 6, C, D, and F, respectively). Finally, the expression of IFN- $\gamma$ mRNA was significantly enhanced in the $\alpha$-GalCer-treated group compared with the control group (Figure 6G), suggesting the contribution of IFN- $\gamma$. In agreement with this possibility, $\alpha-\mathrm{GalCer}-$ induced promotion of wound healing was canceled in IFN- $\gamma \mathrm{KO}$ mice (Figure $6 \mathrm{H}$ ).

\section{Discussion}

The following are the main findings in the present study: i) J $\alpha 18 \mathrm{KO}$ mice show delayed wound repair compared 

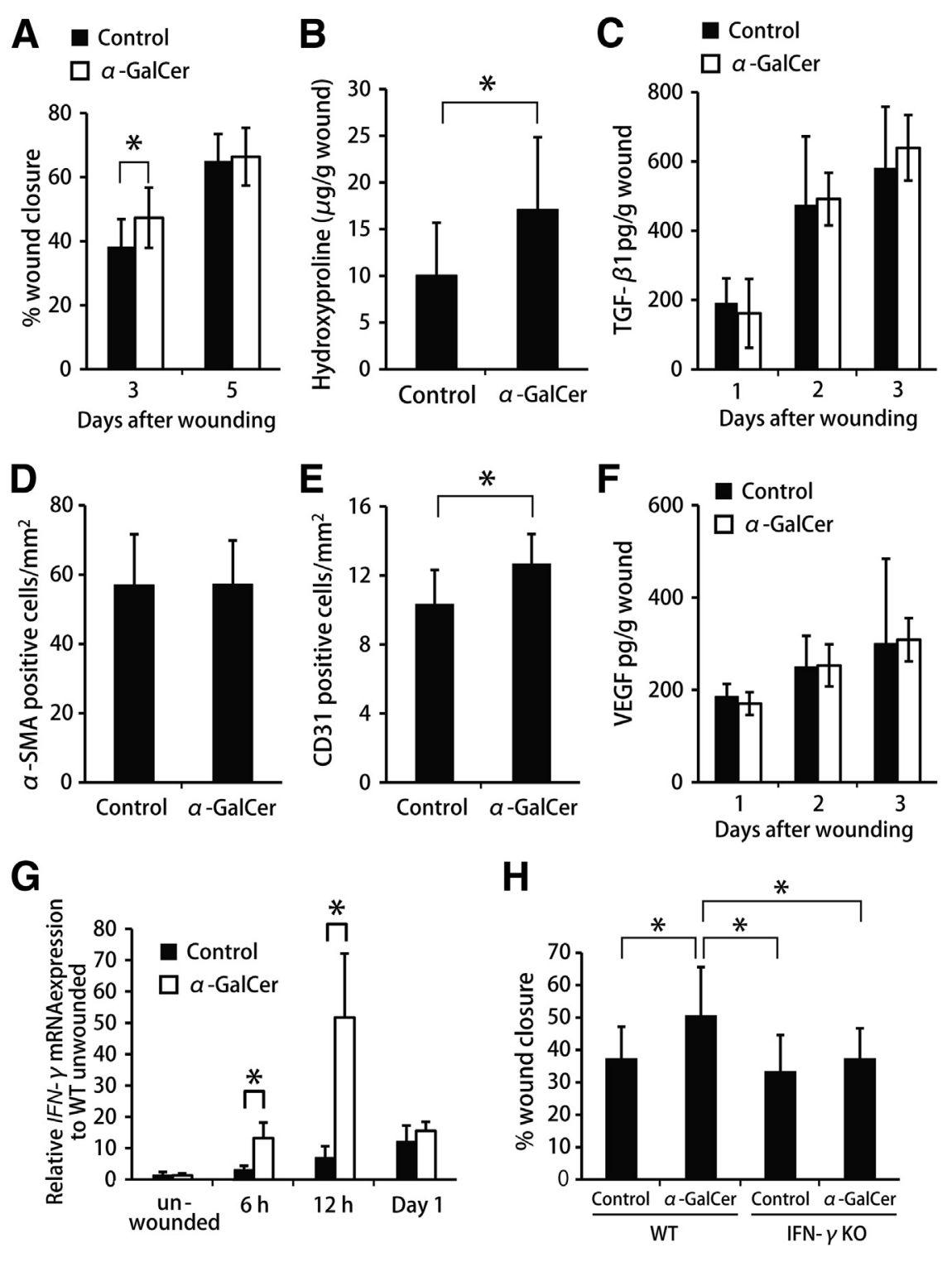

Figure 6 Effect of $\alpha$-GalCer administration on wound healing. WT mice were injected intraperitoneally with $\alpha$-GalCer ( $2 \mu \mathrm{g}$ per mouse) or $0.2 \%$ DMSO on day 1 before wound creation; wounds were created on the back of WT mice. A: Percentage of wound closure was evaluated on days 3 and 5 after wound creation. B: Hydroxyproline contents on day 3 after wound creation. C: Production of TGF- $\beta 1$ in the homogenates of wound tissues was measured on days 1,2 , and 3 after wound creation. $\alpha-\mathrm{SMA}^{+}$cells $/ \mathrm{mm}^{2}$ (D) and $\mathrm{CD} 31^{+}$cells/ $\mathrm{mm}^{2}(\mathbf{E})$ were evaluated on day 3. F: Production of VEGF in the wound tissues was measured on days 1,2 , and 3 after wound creation. G: Expression of IFN- $\gamma$ mRNA in the wound tissues by real-time PCR. H: WT or IFN- $\gamma \mathrm{KO}$ mice were injected intraperitoneally with $\alpha$-GalCer (2 $\mu \mathrm{g}$ per mouse) or $0.2 \%$ DMSO on day 1 before wound creation; wounds were created on the back of mice. Percentage of wound closure was evaluated on day 3 after wound creation. Each column represents the means $\pm S D$. $n=18(\mathbf{A}, \mathbf{B}$, and $\mathbf{H}) ; n=5(\mathbf{C}$ and $\mathbf{F}) ; n=9$ (D and $\mathbf{E}) ; n=6(\mathbf{G})$. ${ }^{*} P<0.05$. DMS0, dimethyl sulfoxide; IFN, interferon; IFN- $\gamma \mathrm{KO}$, IFN- $\gamma$ genedisrupted; TGF, transforming growth factor; VEGF, vascular endothelial growth factor; WT, wild-type; $\alpha$-GalCer, $\alpha$-galactosylceramide; $\alpha$-SMA, $\alpha$-smooth muscle actin.

with WT mice; ii) wound repair-related markers, including hydroxyproline content, COL1A1 expression, $\alpha-\mathrm{SMA}^{+}$cells, CD31 ${ }^{+}$cells, and wound breaking strength, are attenuated in J $\alpha 18 \mathrm{KO}$ mice; iii) TGF- $\beta 1$ and VEGF production decreases in $\mathrm{J} \alpha 18 \mathrm{KO}$ mice; iv) IFN- $\gamma$ expression attenuates at 24 hours, but increases on day 3 in $\mathrm{J} \alpha 18 \mathrm{KO}$ mice; v) the impaired wound closure in $\mathrm{J} \alpha 18 \mathrm{KO}$ mice is reversed by the transfer of LMNCs obtained from WT mice, but not from J $\alpha 18 \mathrm{KO}$ or IFN- $\gamma \mathrm{KO}$ mice; and vi) administration of $\alpha$-GalCer, an activator of $i$ NKT cells, results in accelerated wound repair. These results indicated the critical role of $i$ NKT cells in the process of wound healing.

In the present study, we demonstrated, for the first time, that $i$ NKT cells promoted skin wound healing, which was associated with elevated collagen content and increased myofibroblasts at the wound tissues. Consistent with these findings, NKT cells were accumulated in the wound tissues (Supplemental Figure S1). It is well known that TGF- $\beta$ produced by macrophages promotes the generation of myofibroblasts from some fibroblasts and increases collagen synthesis, which results in the contraction of the extracellular matrix and subsequent wound closure. ${ }^{21-23}$ In this study, TGF- $\beta 1$ production was decreased in $\mathrm{J} \alpha 18 \mathrm{KO}$ mice, suggesting that the decreased collagen deposition and number of myofibroblasts may be due to the reduction of TGF- $\beta 1$ production because of the reduced number of $i$ NKT cells. Similar results were reported, in which the expression of COL1A1, $\alpha$-SMA, and TGF- $\beta 1$ mRNA in the liver was reduced in CD1dKO (NKT-deficient) mice, reaching only one-fourth of that in WT mice given the same agents. ${ }^{24}$ However, angiogenesis is also an important event in the skin wound healing process, and VEGF is essential for the development of angiogenesis. ${ }^{25}$ Hijioka et $\mathrm{al}^{26}$ reported that neovascularization and VEGF expression in a 
photocoagulation-induced choroidal neovascularization model were substantially reduced in $\mathrm{J} \alpha 18 \mathrm{KO}$ and CD1dKO mice. In this study, we also found that the number of $\mathrm{CD} 31^{+}$cells and VEGF production were decreased in $\mathrm{J} \alpha 18 \mathrm{KO}$ mice. During the wound healing, macrophages and fibroblasts are the main source of TGF$\beta$ and VEGF production. ${ }^{4,21}$ These results suggest that $i$ NKT cells may promote collagen deposition, myofibroblast differentiation, and angiogenesis by induction of the production of these cytokines by macrophages and fibroblasts.

The relation between skin wound healing and IFN- $\gamma$ was reported, in which the impaired wound healing in diabetic rats was recovered by the injection of monocyte/macrophages stimulated with TNF- $\alpha$ and IFN- $\gamma \cdot{ }^{27}$ In addition, VEGF production and phagocytic activity were increased in TNF- $\alpha$ plus IFN- $\gamma$-stimulated monocytes/macrophages in vitro. ${ }^{27}$ In contrast, Ishida et $\mathrm{al}^{28}$ showed that IFN- $\gamma$ disrupted the skin wound healing process via inhibition of TGF- $\beta$ production. In the present study, IFN- $\gamma$ expression was substantially reduced in J $\alpha 18 \mathrm{KO}$ mice compared with WT mice in the early phase, suggesting that $i$ NKT cells contribute to wound healing through inducing the early-phase production of this cytokine. In agreement with this notion, the adoptive transfer of LMNCs from WT mice, but not from $\mathrm{J} \alpha 18 \mathrm{KO}$ or IFN- $\gamma \mathrm{KO}$ mice, completely reversed the delayed wound healing and the impaired myofibroblast differentiation and neovascularization in $\mathrm{J} \alpha 18 \mathrm{KO}$ mice, although $i \mathrm{NKT}$ cells were not directly transferred. By contrast, the late-phase expression of IFN- $\gamma$ was substantially increased in $\mathrm{J} \alpha 18 \mathrm{KO}$ mice compared with WT mice. It was also demonstrated that the main source of IFN- $\gamma$ production was neutrophils rather than NK cells and T cells. It is thus evident that the role of IFN- $\gamma$ differs between the early and late stage. In the early phase, IFN- $\gamma$ may activate macrophage phagocytosis and promote VEGF production, but may inhibit TGF- $\beta$ in the later phase, which may be involved in attenuation of the wound breaking strength.

In the present study, we also tested the effect of $\alpha$-GalCer administration on skin wound healing. Activation of $i$ NKT cells by $\alpha$-GalCer enhanced the wound closure, collagen deposition, $\mathrm{CD} 31^{+}$cells, and IFN- $\gamma$ expression. However, the production of TGF- $\beta 1$ and VEGF and the number of $\alpha$ $\mathrm{SMA}^{+}$cells were not increased in $\alpha$-GalCer-administered mice. Earlier studies reported IFN- $\gamma-$ induced suppression in the TGF- $\beta$ production and differentiation of myofibroblasts, ${ }^{29-31}$ which may raise a possibility that excessively produced IFN- $\gamma$ by $\alpha$-GalCer-activated $i$ NKT cells obscures the promotion of TGF- $\beta$ production and the increase in $\alpha-\mathrm{SMA}^{+}$cells during the process of wound healing. Although the reason for the failure of $\alpha$-GalCer to promote all wound healing-related events remains unclear, this mechanism might be involved in the inconsistent effects of $i$ NKT cell activation.

In earlier studies, Schneider et $\mathrm{al}^{14,15}$ reported that wound closure and collagen deposition were accelerated in mice lacking $i \mathrm{NKT}$ cells and mice treated with anti$\mathrm{CD} 1 \mathrm{~d}$ mAb. In contrast, in the present study, the presence of $i$ NKT cells accelerated wound healing. These contrasting results might be caused by differences in the mouse strains (BALB/c versus C57BL/6) or the treatment of wounded sites: left open versus covered with a polyurethane film. In general, BALB/c mice exhibit a $T$ helper cell type 2-dominant immune response, whereas C57BL/6 mice exhibit a $\mathrm{T}$ helper cell type 1-dominant immune response. ${ }^{32}$ Different experimental conditions and immune responses may contribute to these opposite results. Further investigation is necessary to determine the exact mechanism.

\section{Conclusion}

In conclusion, we demonstrated that $i$ NKT cells played crucial roles in the wound healing process and that the agonist affecting their activities enhanced their roles. The present study may therefore shed light on the immunologic mechanisms of wound healing in the skin. This may lead to a novel approach to promote wound healing in chronic wounds.

\section{Acknowledgments}

We thank Drs. Toshinori Nakayama (Chiba University, Chiba, Japan) and Yoichiro Iwakura (Tokyo University of Science, Tokyo, Japan) for their kind gifts of J $\alpha 18 \mathrm{KO}$ mice and IFN- $\gamma \mathrm{KO}$ mice, respectively.

\section{Supplemental Data}

Supplemental material for this article can be found at http://dx.doi.org/10.1016/j.ajpath.2015.08.012.

\section{References}

1. Robson MC, Steed DL, Franz MG: Wound healing: biologic features and approaches to maximize healing trajectories. Curr Probl Surg 2001, 38:72-140

2. Rumalla VK, Borah GL: Cytokines, growth factors, and plastic surgery. Plast Reconstr Surg 2001, 108:719-733

3. Mast BA, Schultz GS: Interactions of cytokines, growth factors, and proteases in acute and chronic wounds. Wound Repair Regen 1996, 4: 411-420

4. Barrientos S, Stojadinovic O, Golinko MS, Brem H, Tomic-Canic M Growth factors and cytokines in wound healing. Wound Repair Regen 2008, 16:585-601

5. Efron JE, Frankel HL, Lazarou SA, Wasserkrug HL, Barbul A: Wound healing and T-lymphocytes. J Surg Res 1990, 48: 460-463

6. Jameson JM, Cauvi G, Sharp LL, Witherden DA, Havran WL: Gammadelta $\mathrm{T}$ cell-induced hyaluronan production by epithelial cells regulates inflammation. J Exp Med 2005, 201:1269-1279

7. Toulon A, Breton L, Taylor KR, Tenenhaus M, Bhavsar D, Lanigan C, Rudolph R, Jameson J, Havran WL: A role for human 
skin-resident T cells in wound healing. J Exp Med 2009, 206: $743-750$

8. Godfrey DI, Hammond KJ, Poulton LD, Smyth MJ, Baxter AG: NKT cells: facts, functions and fallacies. Immunol Today 2000, 21: $573-583$

9. Kronenberg M, Gapin L: The unconventional lifestyle of NKT cells. Nat Rev Immunol 2002, 2:557-568

10. Taniguchi M, Harada M, Kojo S, Nakayama T, Wakao H: The regulatory role of Valpha14 NKT cells in innate and acquired immune response. Annu Rev Immunol 2003, 21:483-513

11. Tupin E, Kinjo Y, Kronenberg M: The unique role of natural killer $\mathrm{T}$ cells in the response to microorganisms. Nat Rev Microbiol 2007, 5: 405-417

12. Kawakami K, Kinjo Y, Uezu K, Yara S, Miyagi K, Koguchi Y, Nakayama T, Taniguchi M, Saito A: Monocyte chemoattractant protein-1-dependent increase of V alpha 14 NKT cells in lungs and their roles in Th1 response and host defense in cryptococcal infection. J Immunol 2001, 167:6525-6532

13. Kawakami K, Yamamoto N, Kinjo Y, Miyagi K, Nakasone C, Uezu K, Kinjo T, Nakayama T, Taniguchi M, Saito A: Critical role of Valpha14+ natural killer T cells in the innate phase of host protection against Streptococcus pneumoniae infection. Eur J Immunol 2003, 33: $3322-3330$

14. Schneider DF, Palmer JL, Tulley JM, Speicher JT, Kovacs EJ, Gamelli RL, Faunce DE: A novel role for NKT cells in cutaneous wound repair. J Surg Res 2011, 168:325-333.e1

15. Schneider DF, Palmer JL, Tulley JM, Kovacs EJ, Gamelli RL, Faunce DE: Prevention of NKT cell activation accelerates cutaneous wound closure and alters local inflammatory signals. J Surg Res 2011, 171:361-373

16. Cui J, Shin T, Kawano T, Sato H, Kondo E, Toura I, Kaneko Y, Koseki H, Kanno M, Taniguchi M: Requirement for Valpha14 NKT Cells in IL-12mediated rejection of tumors. Science 1997, 278:1623-1626

17. Tagawa Y, Sekikawa K, Iwakura Y: Suppression of concanavalin Ainduced hepatitis in IFN-gamma(-/-) mice, but not in TNF-alpha(-/-) mice: role for IFN-gamma in activating apoptosis of hepatocytes. J Immunol 1997, 159:1418-1428

18. Nakamatsu M, Yamamoto N, Hatta M, Nakasone C, Kinjo T, Miyagi K, Uezu K, Nakamura K, Nakayama T, Taniguchi M, Iwakura Y, Kaku M, Fujita J, Kawakami K: Role of interferon-gamma in Valpha14+ natural killer $\mathrm{T}$ cell-mediated host defense against Streptococcus pneumoniae infection in murine lungs. Microbes Infect 2007, 9:364-374

19. Nakamura Y, Sato K, Yamamoto H, Matsumura K, Matsumoto I, Nomura T, Miyasaka T, Ishii K, Kanno E, Tachi M, Yamasaki S, Saijo S, Iwakura Y, Kawakami K: Dectin-2 deficiency promotes Th2 response and mucin production in the lungs after pulmonary infection with Cryptococcus neoformans. Infect Immun 2015, 83: 671-681

20. Chen L, Mehta ND, Zhao Y, DiPietro LA: Absence of CD4 or CD8 lymphocytes changes infiltration of inflammatory cells and profiles of cytokine expression in skin wounds, but does not impair healing. Exp Dermatol 2014, 23:189-194

21. Lucas T, Waisman A, Ranjan R, Roes J, Krieg T, Müller W, Roers A, Eming SA: Differential roles of macrophages in diverse phases of skin repair. J Immunol 2010, 184:3964-3977

22. Goldberg MT, Han Y-P, Yan C, Shaw MC, Garner WL: TNF-alpha suppresses alpha-smooth muscle actin expression in human dermal fibroblasts: an implication for abnormal wound healing. J Invest Dermatol 2007, 127:2645-2655

23. Gabbiani G: The myofibroblast in wound healing and fibrocontractive diseases. J Pathol 2003, 200:500-503

24. Ishikawa S, Ikejima K, Yamagata H, Aoyama T, Kon K, Arai K, Takeda K, Watanabe S: CD1d-restricted natural killer $\mathrm{T}$ cells contribute to hepatic inflammation and fibrogenesis in mice. J Hepatol 2011, 54:1195-1204

25. Olsson A-K, Dimberg A, Kreuger J, Claesson-Welsh L: VEGF receptor signalling - in control of vascular function. Nat Rev Mol Cell Biol 2006, 7:359-371

26. Hijioka K, Sonoda K-H, Tsutsumi-Miyahara C, Fujimoto T, Oshima Y, Taniguchi M, Ishibashi T: Investigation of the role of CD1d-restricted invariant NKT cells in experimental choroidal neovascularization. Biochem Biophys Res Commun 2008, 374: $38-43$

27. Gu XY, Shen SE, Huang CF, Liu YN, Chen YC, Luo L, Zeng Y, Wang AP: Effect of activated autologous monocytes/macrophages on wound healing in a rodent model of experimental diabetes. Diabetes Res Clin Pract 2013, 102:53-59

28. Ishida Y, Kondo T, Takayasu T, Iwakura Y, Mukaida N: The essential involvement of cross-talk between IFN-gamma and TGF-beta in the skin wound-healing process. J Immunol 2004, 172:1848-1855

29. Cornelissen AMH, Maltha JC, Von den Hoff JW, KuijpersJagtman AM: Local injection of IFN-gamma reduces the number of myofibroblasts and the collagen content in palatal wounds. J Dent Res 2000, 79:1782-1788

30. Hinz B: Formation and function of the myofibroblast during tissue repair. J Invest Dermatol 2007, 127:526-537

31. Ulloa L, Doody J, Massagué J: Inhibition of transforming growth factor-beta/SMAD signalling by the interferon-gamma/STAT pathway. Nature 1999, 397:710-713

32. Kuroda E, Noguchi J, Doi T, Uematsu S, Akira S, Yamashita U: IL-3 is an important differentiation factor for the development of prostaglandin E2-producing macrophages between C57BL/6 and BALB/c mice. Eur J Immunol 2007, 37:2185-2195 